\title{
Humanising the curriculum: The role of a Virtual World
}

\author{
Beverley Ewens ${ }^{* 1}$, Sara Geale ${ }^{2}$, Caroline Vafeas ${ }^{1}$, Fiona Foxall ${ }^{1}$, Barbara Loess ${ }^{1}$, Aisling Smyth ${ }^{1}$, Christopher \\ McCafferty ${ }^{1}$ \\ ${ }^{1}$ Edith Cowan University, Perth, Western Australia, Australia \\ ${ }^{2}$ Newcastle University, Callaghan, Australia
}

Received: April 27, 2016

DOI: $10.5430 /$ jnep.v6n12p80
Accepted: July 19, 2016

URL: http://dx.doi.org/10.5430/jnep.v6n12p80

\begin{abstract}
Objective: Technology has changed our world; changed the way we communicate, the way we do business and the way education is delivered. As a result, undergraduate student cohorts come to university equipped with new technology, and educators need to transform the delivery of the curricula to satisfy a variety of learning styles. Nursing education, in particular, is developing and transforming to incorporate technology into the learning environment. Clinical placement opportunities are often sparse and alternative experiences need to be considered. Across nursing curricula, it has been recognised that technology has the capacity to provide real-life learning experiences that promote student engagement and meet the learning needs of a diverse student cohort. Methods: This paper will discuss the development of a "Virtual World" in an undergraduate nursing program in Western Australia. The Virtual World initiative is designed to support students to understand the holistic, health-centred intent of the curriculum. Results: Initial results have shown that the Virtual World and humanising the curriculum, has increased learner engagement, improved critical thinking and decision-making. It has enhanced and maintained a high level of student satisfaction and selfefficacy as well as assisting the development of graduate nurses who perceive themselves as health advocates, problem-solvers and organisers of care. Research will continue to follow the use of the Virtual World model, incorporating a virtual family and its integration into the undergraduate nursing curriculum.

Conclusions: In the current climate of nurse education and due to a reduction in availability of clinical placements, alternative authentic experiences need to be offered. The development of the Virtual World has enabled meaningful participation in a safe and supportive learning environment.
\end{abstract}

Key Words: Higher education teaching and learning, University teaching, Learning and curriculum design, Virtual world, Simulation, Pedagogy, Nursing education

\section{INTRODUCTION}

Educators in tertiary institutions have the perception that students who now enter university are of the "net generation" and "digital natives", ${ }^{[1]}$ equipped with new technology and the expectation of utilising this technology for their studies. However, there is evidence that students do not necessarily expect or want to use technology at school and that they might not have the skills or the means to use it. ${ }^{[1]}$ Whilst many students do use new technology, they are also aware of the negative aspects. A recent Office of Teaching and Learning (OLT) funded study by Selwyn and colleagues identified that whilst $71 \%$ of university students use their smartphones and $74 \%$ their tablets for academic work, many of them describe Facebook, You Tube and smartphones as

*Correspondence: Beverley Ewens; Email: b.ewens@ecu.edu.au; Address: Edith Cowan University, Perth, Western Australia, Australia. 
procrastination and distraction tools. ${ }^{[2]}$ There is clearly a place for technology within a tertiary education setting but it has to be utilised appropriately.

Nursing education has been evolving to incorporate technologies into the learning environment. There is a growing body of evidence that technology and the online environment is changing the way in which education is being delivered for the benefit of both student and educator. ${ }^{[3]}$ The value of technology and its capacity to provide real-life learning experiences that promote student engagement and meet the learning needs of a diverse student group, have been recognised within nursing curricula. ${ }^{[4]}$

Incorporated technologies include the development of Virtual Worlds in which the student can practise patient care in true to life clinical scenarios within a safe environment. A Virtual World platform has the capacity to provide a computerbased multimedia environment in which students play the role of health care provider in a variety of clinical settings. ${ }^{5]}$ Students gain a range of fundamental experiences such as performing health assessments, patient interviews and other important skills, whilst interacting with virtual patients in the safe supportive environment of a Virtual World. The student can engage in scenarios that range from the delivery of basic care to advanced critical care situations in which they are called upon to recognise and manage the deteriorating patient. All of this takes place in authentic environments and contexts but without risk to the patient or the student.

Evidence suggests that there are positive benefits for students with the addition of Virtual Worlds that support a realistic learning environment within a curriculum, such as increased learner engagement, improved critical thinking, decision-making, and self-efficacy as well as a high level of student satisfaction. ${ }^{[6-9]}$ Giddens and colleagues ${ }^{[10]}$ indicated that students were able to gain an understanding of the lived experiences of Virtual World characters from various demographic and cultural backgrounds, contributing to the development of their cultural awareness. In some cases this exposure to different people and contexts may not be available during the students' clinical placements in the current climate of paucity of clinical placements.

In nursing education, students hail from a diversity of backgrounds. An example of this diversity is within an undergraduate nursing program offered both in metropolitan Perth and at a regional campus in Western Australia which has a large percentage of mature age students (51\% regional and $25 \%$ metropolitan campus). There is no formal data on first-infamily enrolments within this cohort, however, $41 \%$ of the regional population over the age of 15 had not progressed beyond year ten, only $38 \%$ had completed year 12 educa- tion and only $16 \%$ hold a bachelor degree. ${ }^{[11]}$ As a result of this diversity many students have competing responsibilities, which can impact upon their ability to attend campus during university hours. The use of technology can ensure that students have access to a range of educational resources without being compelled to attend campus.

In 2013, a new curriculum was developed with the intent of catering for the needs of a diverse student cohort. The focus of the curriculum shifted from an acute care centric course, to one that was both more contemporary and holistic in its approach and was to incorporate an enhanced online virtual learning platform. Online programs incorporating technologies such as Virtual Worlds have wide appeal due to their convenience, accessibility and flexibility for those who require it. ${ }^{[12]}$

This paper will discuss the experiences of developing a Virtual World as an integral component of a new undergraduate nursing curriculum with the aim of improving the student learning experience, whilst creating a cohesive whole-ofcourse approach to the curriculum. Preliminary research into the introduction and implementation of the Virtual World and the future of this initiative will also be discussed.

\subsection{Background}

Nursing graduates today are employed within in a variety of health care contexts. These contexts will continue to diversify in the 21 st century as a result of population trends and the changing health care needs of both the Australian and international communities. ${ }^{[13]}$ It is the responsibility of nursing educators to prepare graduate nurses to deliver safe, effective patient-centred care within this evolving and challenging health care environment. The new curriculum for the three-year undergraduate nursing program has an holistic and patient-centred focus, with emphasis on the current National Health Priorities. ${ }^{[14]}$ It focuses attention on the health of populations across the human lifespan, with the intent to prepare the nursing workforce for the challenges associated with global changes to demographics and health care. The aim of this curriculum is also to reinforce professionalism as the driver for communication, teamwork and inter-professional practice.

Age-related needs are also addressed in the curriculum, as determined by the patient, rather than the healthcare provider, in units of study relating to adult health, older adult health and child and adolescent health. The curriculum content is organised around the health and wellness of the population and of specific population groups. The program also integrates those factors that affect health status to support the concept that the role of a registered nurse is not just that of a 'doer of 
tasks' but rather he or she is that of an active, professional member of a healthcare team, in which the patient and their families are partners in care.

The role of the graduate nurse is to act as a health advocate, problem-solver, knowledgeable worker, and organiser of care. These concepts are reinforced in the Virtual World through the use of case studies and scenarios, encouraging students to follow and connect with virtual patients and their families throughout their health care journey. Inquiry Based Learning (IBL) and Kolb's Experiential Learning Model ${ }^{[15]}$ are the theories which underpin this learning trajectory. Inquiry Based Learning is a well-supported pedagogical approach in higher order learning and is practiced in a wide range of disciplines in both undergraduate and postgraduate programs. ${ }^{[16]}$

To facilitate an IBL approach and to provide a coherent study pathway, the curriculum framework is structured around three streams: nursing concepts and skills, applied health sciences and professional nursing practice. The nursing concepts and skills stream exposes students to the knowledge and attitudes that provide the foundation for safe, effective nursing practice comprising scenarios that require the application of knowledge and theoretical concepts to the practice situation. The applied science units support the development of knowledge and understanding, as well as the application of physiology, pathophysiology and pharmacology that inform the practice of a registered nurse (RN). The professional nursing practice stream is designed to provide students with the practical application of the knowledge, attitudes and skills that are required for their clinical placement experiences and their professional practice as an RN.

The professional nursing practice units of study incorporate low, intermediate and high fidelity simulation activities to prepare students for placements and are supported by the use of the new national clinical assessment tool. Specific concepts are developed progressively over the undergraduate journey with patient safety and quality in the provision of evidence-based and cost-effective care as the essential underpinning of the curriculum and its delivery. These concepts are addressed early, scaffolded progressively through the curriculum and are interwoven throughout the three streams. The developers were cognisant that technology needed to support the curriculum and its delivery, rather than lead it. Biggs $^{[17]}$ described constructive alignment as providing a framework within which students are able to construct meaning through undertaking learning activities that are relevant to the stated learning outcomes. Constructive alignment informed the new curriculum and drew together the relationship between intended curriculum outcomes, student performance and learning resources. ${ }^{[6]}$ The use of technology strengthens the qualitative and holistic approach of the new curriculum. The development of the Virtual World with a virtual family is therefore an integral component of this approach.

\subsubsection{The virtual world model}

The Virtual World learning platform was designed with the intent of supporting the new curriculum to achieve the stated goal of focusing students on the needs of their patients across a lifespan continuum, compared to traditional health delivery models. It was also designed to support the holistic healthcentred curriculum. Importantly, the virtual family; situated within the Virtual World is a fundamental component of it and has been scaffolded and integrated across this curriculum. ${ }^{[18]}$ The Virtual Family and the world in which they live, provide students with an integrated and authentic humanistic experience. The Virtual World learning platform comprises a range of applications including a virtual family, depicted in a family tree (see Figure 1). Each member of the family has their own health story from which case studies and clinical practice scenarios can be derived. Videos that portray patient care scenarios using actors assuming patient and care-giver roles; actors using realistic character silicone masks in simulated ward settings; low, intermediate and high fidelity manikins in simulated hospital wards; as well as a gaming platform that enables students to simulate care-giving off-campus and outside of routine university hours are all components of the Virtual World (see Figure 2).

The incorporation of the Virtual World into the curriculum ensures that students achieve the intended learning outcomes in a planned and progressive manner, without omissions or unnecessary duplication of student and staff effort. The family members were created to incorporate a lifespan continuum and the technology was carefully mapped to support the integrity of the curriculum, the essential relationship between professionalism, communication and teamwork, informing the learning outcomes and therefore the assessment strategies. ${ }^{[18]}$

\subsubsection{Simulation facilities}

The University's School of Nursing and Midwifery boasts state of the art simulation facilities within several ward settings. These wards are equipped with the essential components of an acute care setting, such as piped oxygen, suction, a nurses' station and both low and high fidelity manikins. Evidence indicates that the use of simulation as a tool to support nursing practice placements is an effective learning strategy both at basic and advanced levels. ${ }^{[19-21]}$ The ability to simulate real-life situations supports improved safety for the patient and for the health care practitioner. ${ }^{[22]}$ The complexity of the simulations is scaffolded, with low-fidelity 
manikins being used in the first and second year nursing practice units and high-fidelity manikins being used in the third year units. The use of simulation for patient care helps to reduce student anxiety prior to practicum and allows for safe practice of skills such as insertion and removal of an indwelling catheter, removal of sutures as well as simple and complex dressings. ${ }^{[22]}$

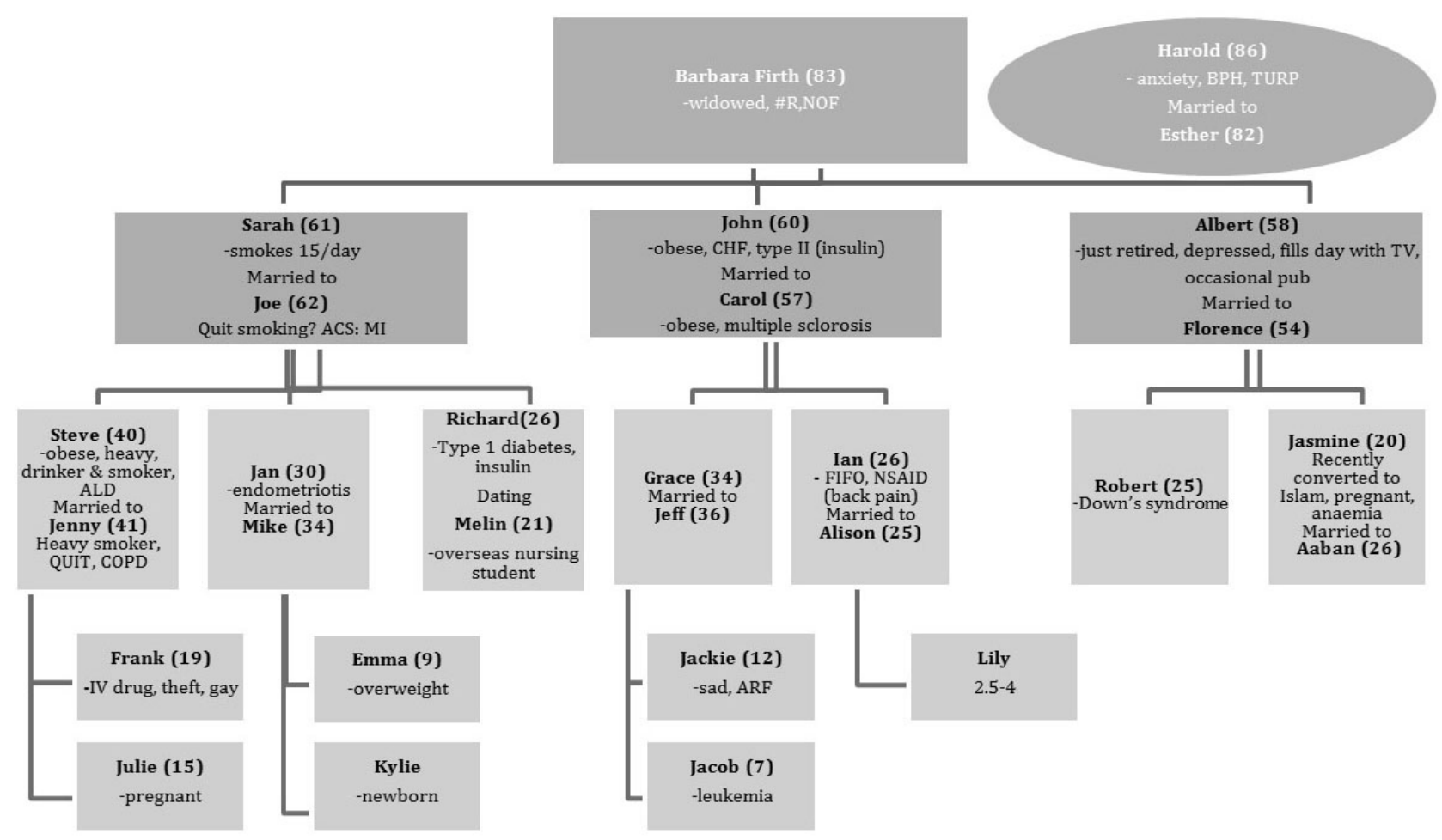

Figure 1. The Virtual Family Tree

Recognition of the deteriorating patient is paramount in national health priorities and use of the high-fidelity manikins in the later stages of the program allows the nursing student to identify and respond appropriately to the deteriorating patient. Simulating the use of infection control procedures, patient identification, and support of patient functionality to reduce falls risks and pressure injuries, supports the development of nurses who can operate at a level that allows them to be health advocates, problem-solvers, knowledgeable workers, and organisers of care.

\subsubsection{Videos}

A series of videos have been developed that are used throughout the different stages of the program and across the three curriculum streams. In the professional nursing practice units, videos are used to demonstrate skills using the latest evidence-based research and its application to practice. Actors in life-like, silicone masks take the role of virtual family members and academic and technical staff play the roles of Registered Nurses, who demonstrate the delivery of care in a holistic and evidence-based manner. These videos are not simply demonstrations of the steps in a skill; instead they depict the development of therapeutic relationships in which patients take part in the decision-making process regarding their health care. Therefore, students are also enlightened regarding the significant impact that effective, evidence-based nursing care can have on an individual's health and wellbeing.

In the nursing concepts and skills stream, a diverse range of videos is used to support development of the knowledge, skills and attitudes necessary for professional nursing practice. For example, in a unit entitled 'professional capacity building', students watch videotaped interviews of senior nurses who have achieved advanced roles or recognition in a specific area of practice or study, to which the students may wish to aspire. Nurse managers, nurse researchers and specialist nurses discuss their roles and the journey they took to achieve the positions they currently hold, assisting students to develop professional development plans.

Animated video clips are also available to clarify aspects of pathophysiology in the applied science stream. All videos are available on the learning management system for students to access at any time. The videos for the professional nursing 
practice stream are available for reference even when the student has completed a specific unit of study. The intent is that the student can return to the videos for reference outside of the classroom and routine university hours. The all-inclusive nature of the videos supports not only the development of clinical skills but also focuses on professionalism, evidencebased practice and the patient-centred approach to health care that is required for 21 st century nursing.

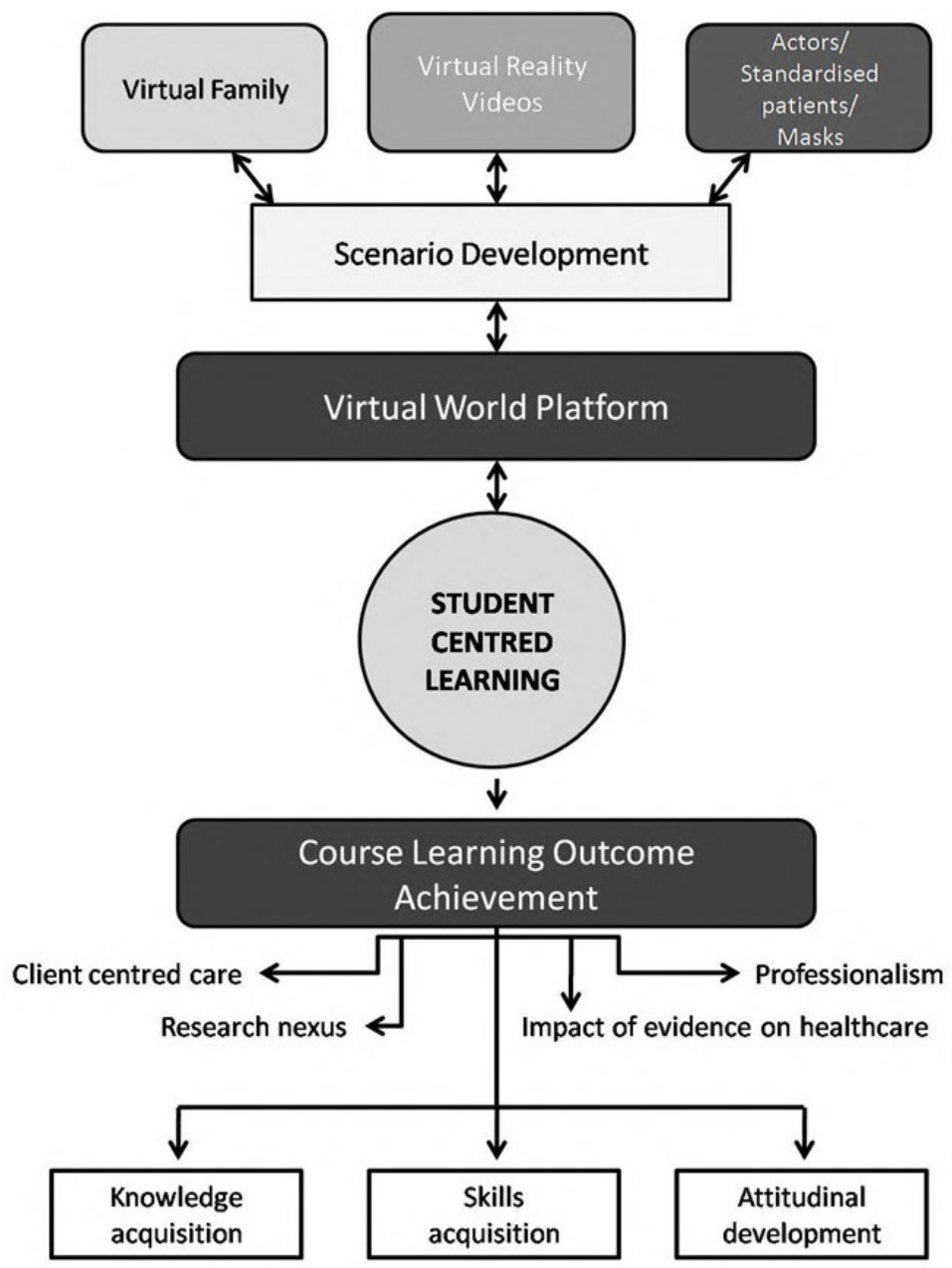

Figure 2. The Virtual World Model

\subsubsection{The virtual family}

The mainstay of the move to engage the students in realworld situations and support the development of the knowledge, skills, and attitudes required for safe, effective nursing practice was the development of the virtual family. The virtual family is built around two siblings who have partners, children, grandchildren and friends. Like all families, the members of this family have stories to tell. There are intercultural and interracial marriages and relationships and the family members face life challenges as well as some of life's joys. Care was taken not to develop a family that had more than their normal share of health burdens. The characters have been carefully developed to represent an everyday family with everyday health and social issues.

According to Biggs, ${ }^{[17]}$ students need to be highly engaged in learning at a level that supports applying knowledge, theorising and critically reflecting. To achieve this level of engagement, the learning environment should include realworld work activities where possible. Currently, clinical placements for students are at a premium and the Virtual World is a new approach to offer students authentic learning experiences to enhance their clinical placement experiences and support their future professional practice. The Virtual World provides those real-world learning situations in a safe, supportive environment because of the range of applications it provides. Students can view videos of the family members receiving evidence-based care, nurse virtual patients in both low and high-fidelity simulations, and use familiar gaming technology to care for the patients in the safe haven of a structured virtual environment. 
In Australia, the population is living longer and those aged over 65 years in 2014 made up $28 \%$ of the population. ${ }^{[23]}$ Australia has a diverse demographic with a population which has just peaked at 24 million people and which is increasing, with fertility rates at an all-time high since 1977. Indigenous Australians were estimated at about 550,000 (1.3\%) of the population ${ }^{[24]}$ and a significant percentage of the total Australian population were born overseas. In Australia, the top 20 specific causes of death were noted to be responsible for $67.2 \%$ of all deaths. ${ }^{[25]}$ In 2014, Ischaemic Heart Disease remained the leading cause of mortality in both genders, with lung cancer, cardiovascular disease, and chronic obstructive pulmonary disease having a significant impact on the health of the population. ${ }^{[25]}$ Other cancers, dementia and diabetes also form a significant part of the health burden in Australia with its urban, rural, and remote populations. ${ }^{[24]}$ Considering this demographic information on the demographic landscape in Australia, characters were developed who could provide the students with meaningful real-life care learning opportunities.

For instance, the main character, the matriarch of the family; Barbara Firth, fell and fractured her hip and required hospitalisation for surgery. Barbara's hospitalisation allows a focus on perioperative care and rehabilitation services. Barbara's brother, Harold, is reasonably fit but his wife, Esther, has been diagnosed with Alzheimer's disease complicated by a stroke 12 months previously leaving her with mild rightsided weakness. Students in their initial professional nursing practice unit, care for Esther from admission for her stroke to discharge from a rehabilitation setting. Esther's story allows the students to focus on patient safety including the application of infection control best practice, falls risk scoring, pressure injury risk, and the activities of daily living, which are all integrated into the simulation settings and scenarios during their weekly workshops in the demonstration wards.

The unit of study in which students cover life-span development, incorporates several family members to demonstrate health and wellness through different developmental stages. The characters are layered with supporting background information that reveal their vulnerability and offer an insight into the challenges they face on a daily basis. Robert, 26, has Type 1 Diabetes, diagnosed when he was 14 and has now developed diabetic ketoacidosis whilst travelling overseas to see his girlfriend in China. He collapses when exercising, offering an opportunity for neurological and peripheral vascular observation, fluid balance monitoring, and patient education. Barbara highlights ethical issues concerning consent and respect for autonomy when she refuses to be taken to hospital in an ambulance when she fractures her hip. Barbara's daughter Carol suffers health issues related to obesity including Type 2 Diabetes and shortness of breath on exertion. Ian Firth is a 'fly in-fly out' (FIFO) worker and is married to Alison, who is 12 weeks pregnant. Robert has Downs Syndrome and Hannah has a school-friend who has asthma.

All these, true-to-life situations challenge the student to think "outside the box" and to consider the patient as an individual with decision-making rights about their health care. As these case studies are also incorporated into two of the applied science units, students are able to discuss possible causes, pathophysiology, diagnostic tools, pharmacological and nonpharmacological treatments, and pathways for care in an environment in which they are supported to make decisions about nursing care, based on best evidence. Stories of the virtual family members are interwoven across the curriculum to support the building of knowledge, skills and attitudes and human experience. The family develops with the student as they all continue their journeys through study and life (see Figure 1).

\subsubsection{Gaming platform}

The aim of the gaming platform is to develop an online medium that houses all Virtual World resources in the format of a 3D model, including audio-visual resources and assessment elements in a central repository. An important criterion is user-friendliness. The platform must have the ability for students to have secure access to the resources both on and off-campus, to accommodate alternative internet connections and hardware including future electronic applications, such as tablets and smartphones. Additionally, the platform software should be: synchronous with the learning management system; allow tutors to track a student's progress; enable students to access assessment results, and the provision of feedback to students. Finally, the platform must allow students to review previous scenarios, such as pertinent patient histories from previous units.

Thus, Unity 3D (http://unity3d.com/) was chosen as the 3D simulation platform as it appears to be the software of choice by other industries that produce medical simulation models. Simulations developed within Unity 3D have the ability to be published to a number of end-points including iOS devices (iPad and iPhone), android devices and Sharable Content Object Reference Model (SCORM)-enabled web modules. SCORM allows web-based e-learning modules to be directly integrated with learning management systems like Blackboard, and work is underway to allow quizzes that are built using the 'Respondus' software to be automatically loaded and presented in Unity 3D simulations. In order to help with maintainability and file size, many of the video (and other) assets will be stored on a web server that can 
present files over the internet. Basically, the 3D platform will reference audio video files and other assets from a centrally based shared drive. Development of this part of the Virtual World is currently underway and has proven to be the most challenging part, as specialised expertise is required to develop it.

\section{Preliminary evaluation}

A research nexus has been built into several of the units to determine if the students are relating to, and benefitting from the integration of technology into their learning experience. A survey, using a Likert scale, was sent to all first-year undergraduate students in the professional nursing practice stream to determine their level of satisfaction with the integration of the virtual world into their lectures, tutorials and laboratory sessions. This first semester unit uses a virtual patient to teach basic patient care and health assessment skills. Videos of the skills taught in the unit are available for review prior to the workshops. There are introductory tutorials that provide students with the background for the skills they will be practicing in the workshops. When students attend the workshops, they are expected to treat the demonstration ward as they would a hospital ward and should act in the same manner as they would whilst on placement. They receive a handover report, then practice patient identification, form a therapeutic relationship with the patient, obtain consent for interventions and assess the patient's health status using the information from the handover report as a guide to the activities to be undertaken. All nursing care is documented in the patient's nursing notes and the students complete their 'shift' with a handover report to the incoming staff.

The initial results have been positive and will be reported in detail in future publications. Students were asked if the workshops using a virtual patient each week aided their understanding of the knowledge and skills required for nursing practice. They were also asked if the workshops helped them to acquire a structure for caring for patients and if they considered that the use of a virtual patient helped support safe practice. The students were also given the opportunity to comment on the unit overall; the results of the survey and the comments generally, were very positive. Students stated that they enjoyed the unit and it helped to build their skills, strengthened their professional approach and allowed them to establish positive relationships with other students. The students also stated that the simulation in the unit enhanced their understanding of the organisation and operationalisation of a hospital ward, as their exposure to clinical settings is minimal throughout their undergraduate program (840 hours in total).

A total of 402 third year students, across both campuses, who were the first cohort of students to complete all of the five applied science units of the new curriculum, were also asked to complete a survey in July 2015. The response rate was $22.14 \%$ with 89 surveys started and 79 completed. Only $22 \%$ of the respondents provided free text answers. The survey, using a four-point Likert scale, related mainly to the content and assessment strategies in the units but a small number of the statements related specifically to the Virtual World and its efficacy. One of the statements related to the virtual family case studies and scenarios used in tutorials and as a form of assessment in two of the units. For the statement "The case studies are very useful and relevant to clinical practice" $70 \%$ of participants $(n=74)$ marked "agree" and $20 \%$ "strongly agree" whilst $10 \%$ marked "disagree" but no students marked "strongly disagree". Results for the statement "As the case studies used in the unit were all related to members of the virtual family, it helped me to link the content of different units and remember things more easily because I have come across the virtual family in other units", were $14 \%$ "strongly agree" 68\% "agree", 15\% "disagree" and 3\% "strongly disagree". Free text answers to the question relating to how the delivery of the applied science units could be improved included: "Webinars would be good, meeting real-life people with real disorders would also be great"; "More interactive software"; "More videos, quizzes, good scenario examples and case studies". The results demonstrated that the students appreciate the Virtual World and would welcome further similar activities.

\section{Findings}

Initial results have shown that the Virtual World and humanising the curriculum, has increased learner engagement, improved critical thinking and decision-making. It has enhanced and maintained a high level of student satisfaction and self-efficacy as well as assisting the development of graduate nurses who perceive themselves as health advocates, problem-solvers and organisers of care. Research will continue to follow the use of the Virtual World model, incorporating a virtual family and its integration into the undergraduate nursing curriculum and following with surveys to students and to the educators/facilitators who use the virtual family in the teaching sessions in the clinical laboratories, tutorials and lectures.

\section{Future outLoOK}

This ongoing research will continue to allow the educators to monitor the use of the virtual family and other components of the virtual world. It will also contribute to the further evaluation of the use of simulation with low, intermediate and high-fidelity manikins in a simulated hospital ward setting. Educators will be enabled to determine if the curriculum 
and learning experience of students is further enhanced by the gaming platform, which allows students to simulate the delivery of nursing care and to explore difficult theoretical concepts whilst off-campus and outside of routine university hours. The focus of the Virtual World and all its facets is to provide the student with real-world situations in which they can enhance their knowledge, understanding and skills that are required to provide safe, effective nursing care to a variety of patients from different cultural backgrounds and with differing co-morbidities.

\section{Conclusion}

The humanising of the curriculum is aimed at capturing the way in which nursing students communicate with health care users. Whilst clinical competencies and skills are achieved through demonstration and practice in workshops and students' private study, the students' progress through the curriculum experiencing patient care situations, which become increasingly complex and involve inter-professional learning experiences. The focus of these experiences is not only on clinical competencies and skills development but also on holistic health care, using a patient and family-centred lifespan approach. Further development of and research into the use of the Virtual World, the virtual family and its integration into the undergraduate nursing curriculum will continue, with the clear intent of supporting reflection, self-understanding and capacity building in nursing students. The pressure on clinical placements is unlikely to abate in the current health care climate and the Virtual World platform offers students an authentic learning experience, which complements and builds upon their clinical practice and classroom experiences.

Humanising the curriculum with the integration of a Virtual World increases learner engagement, improves critical thinking and decision-making, and achieves a high level of student satisfaction and self-efficacy. Ultimately, it is envisaged that this will result in the development of graduate nurses who see themselves as health advocates, problem-solvers, knowledgeable practitioners, organisers of care, change agents and nursing leaders of the future.

\section{REFERENCES}

[1] Selwyn N. The digital native-myth and reality. Aslib Proceedings. 2009; 61(4): 364-379. http://dx.doi.org/10.1108/0001253 0910973776

[2] Cervini E. Time to ask students about use of digital technologies in lectures. The Sydney Morning Herald. 2015 June. Available from: http://www.smh.com.au/action/printArticle ?id $=997133766$

[3] Green J, Wyllie A, Jackson D. Virtual worlds: a new frontier for nurse education? Collegian. 2014; 21(2): 135-141. http: //dx.doi.org/10.1016/j.colegn.2013.11.004

[4] Levett-Jones T, Bowen L, Morris A. Enhancing nursing students' understanding of threshold concepts through the use of digital stories and a virtual community called 'Wiimali'. Nurse Educ Pract. 2015; 15(2): 91-6. PMid:25487056 http://dx.doi.org/10.1016/j.n epr.2014.11.014

[5] De Gagne JC, Oh J, Kang J, et al. Virtual worlds in nursing education: A synthesis of the literature. Journal of Nurse Education. 2013; 52(7): 391-396. PMid:23755942 http://dx.doi.org/10.3928/01484 834-20130610-03

[6] Cant RP, Cooper SJ. Simulation in the Internet age: The place of web-based simulation in nursing education. An integrative review. Nurse Education Today. 2014; 34(12): 1435-1442. PMid:25156144 http://dx.doi.org/10.1016/j.nedt.2014.08.001

[7] Gonzalez L, Fenske CL. Use of a virtual community to contextualize learning activities. Journal of Nurse Education. 2012; 51(1): 38-41. PMid:22132719 http://dx.doi.org/10.3928/01484834-201 11130-04

[8] Hardy J, Drury P, Frotjold A, et al. Developing critical thinking skills in undergraduate nurses using information and communication technologies. Nursing Monograph. 2003; 6-8.

[9] Sowan AK, Idhail JA. Evaluation of an interactive web-based nursing course with streaming videos for medication administration skills.
International Journal of Medical Informatics. 2014; 83(8): 592 600. PMid:24930589 http://dx.doi.org/10.1016/j.ijmedin f. 2014.05 .004

[10] Giddens JF, North S, Carlson-Sabelli L, et al. Using a virtual community to enhance cultural awareness. Journal of Transcultural Nursing. 2012; 23(2): 198-204. PMid:22294335 http://dx.doi.org/10. $1177 / 1043659611434061$

[11] Department of Training and Workforce Development. South West workforce development plan 2013-2016. 2013. Available from: http://www.dtwd.wa.gov. au/workforceplanninganddev elopment/regionalworkforcedevelopmentplans/Documen ts/SouthWest_Plan_web.pdf

[12] Dorrian J, Wache D. Introduction of an online approach to flexible learning for on-campus and distance education students: Lessons learned and ways forward. Nurse Education Today. 2009; 29(2): 157 167. PMid:18954922 http://dx.doi.org/10.1016/j.nedt. 20 08.08 .010

[13] Matthews L, Pockett R, Nisbet G, et al. Building capacity in Australian interprofessional health education: Perspectives from key health and higher education stakeholders. Australian Health Review. 2011; 35(2): 136-140. PMid:21612723 http://dx.doi.org/10. 1071/AH10886

[14] Australian Commission on Safety and Quality in Health Care. National Safety and Quality Health Service Standards. 2012. Available from: http://www.safetyandquality.gov.au

[15] Kolb D. Experiential Learning: Experience as the Source of Learning and Development. 2015. 2nd ed. Upper Saddle River, New Jersey. Pearson Education.

[16] Aditomoab A, Goodyear P, Bliuc A, et al. Inquiry-based learning in higher education: Principal forms, educational objectives, and disciplinary variations. Studies in Higher Education. 2013; 38(9): 12391258. http://dx.doi.org/10.1080/03075079.2011.616584 
[17] Biggs JT. Applying constructive alignment to outcomes-based teaching and learning. Training material for quality teaching for learning in higher education: Workshop for master trainers. 2010 February; 23-25.

[18] André K, Witney C. Edith Cowan University School of Nursing and Midwifery: Bachelor of Science (Nursing) Curriculum Redevelopment. 2011. Edith Cowan University.

[19] Khalaila R. Simulation in nursing education: An evaluation of students' outcomes at their first clinical practice combined with simulations. Nurse Education Today. 2014; 34(2): 252-258. PMid:24060462 http://dx.doi.org/10.1016/j.nedt.2013.08.015

[20] Smith PC, Hamilton BK. The effects of virtual reality simulation as a teaching strategy for skills preparation in nursing students. Clinical Simulation in Nursing. 2015; 11(1): 52-58. http: //dx.doi.org/10.1016/j.ecns.2014.10.001
[21] Stroup C. Simulation usage in nursing fundamentals: Integrative literature review. Clinical Simulation in Nursing. 2014; 10(3): e155e164.

[22] O'Connor T. The role of simulation in nursing education. Kai Tiaki: Nursing New Zealand. 2014; 20(1): 11-12.

[23] Australian Bureau of Statistics. Who are Australia's older people? Reflecting a nation: Stories from the 2011 census. 2012. Available from: http://www.abs.gov.au/ausstats/abs@.nsf /Lookup/2071. Omain+features752012-2013

[24] Australian Institute of Health \& Welfare (AIHW). Australia's health 2010. (Vol. AUS 122). 2011. Canberra: Australian Institute of Health and Welfare.

[25] Australian Bureau of Statistics. Causes of death Australia 2013. 2015. Available from: http: //www .abs.gov. au/ausstats\%5Cabs@.n sf/0/47E19CA15036B04BCA2577570014668B?Opendocument 